\title{
Adaptive physical activity improves mobility function and quality of life in chronic hemiparesis
}

\author{
Richard F. Macko, MD; ${ }^{1-3}$ Francesco Benvenuti, MD; ${ }^{4}$ Steven Stanhope, PhD; ${ }^{5}$ Velio Macellari, DrEng; 6 \\ Antonia Taviani, MD; ${ }^{4}$ Barbara Nesi, PT; ${ }^{4}$ Michael Weinrich, MD; ${ }^{7}$ Mary Stuart, $\mathbf{S c D}{ }^{1,8}$ \\ ${ }^{1}$ Geriatric Research, Education, and Clinical Center, Department of Veterans Affairs (VA) Maryland Health Care \\ System, Baltimore VA Medical Center (VAMC) Baltimore, MD; ${ }^{2}$ VA Rehabilitation Research and Development Exercise \\ and Robotics Center of Excellence, Baltimore VAMC, Baltimore, $M D ;{ }^{3}$ Departments of Neurology and Medicine, \\ Division of Gerontology, University of Maryland School of Medicine, Baltimore, MD; ${ }^{4}$ Dipartimento della Riabilitazi- \\ one, Azienda Unità Sanitaria Locale 11, Regione Toscana, Empoli, Italy; ${ }^{5}$ National Institutes of Health (NIH), Physical \\ Disabilities Branch, Bethesda, MD; ${ }^{6}$ Reparto Biomeccanica e Tecnologie Riabilitative, Dipartimento Tecnologie e \\ Salute, Istituto Superiore di Sanità, Roma, Italy; ${ }^{7} \mathrm{NIH}$, National Institute of Child Health and Human Development, \\ Bethesda, MD; ${ }^{8}$ Departments of Sociology and Anthropology, University of Maryland, Baltimore County, Baltimore, MD
}

\begin{abstract}
This study investigated the effects of an adaptive physical activity (APA) program on mobility function and quality of life (QOL) in chronic stroke patients. Twenty subjects with chronic hemiparesis completed a 2-month, combined group, class-home exercise regimen that emphasized mobility training. APA improved Berg Balance Scale scores (35 +/2 vs $45+/-2, p=0.001)$, 6 -minute walk distances (114 +/15 vs $142+/-7$ m, $p<0.001$ ), and Short Physical Performance Battery scores $(3.2+/-0.4$ vs $5.2+/-0.6, p<0.001)$. Barthel Index scores increased ( $75+/-4$ vs $84+/-4, p<0.001$ ), but Lawton scores were unchanged. Geriatric Depression Scale $(p<0.01)$ and Stroke Impact Scale (SIS), Mobility, Participation, and Recovery improved with APA $(p<0.03)$. APA has the potential to improve gait, balance, and basic but not instrumental activities of daily living profiles in individuals with chronic stroke. Improved depression and SIS scores suggest APA improves stroke-specific outcomes related to QOL.
\end{abstract}

Key words: activities of daily living, adaptive physical activity, exercise, group exercise, hemiplegia, home exercise regimen, mobility, quality of life, rehabilitation, stroke.

\section{INTRODUCTION}

Many stroke survivors have chronic deficits that limit physical activity and cause subsequent physical deconditioning, which propagates disability and worsens cardiovascular disease risk [1-3]. Exercise can improve ambulatory function and fitness even years after stroke [47]. Yet few studies have considered the design of exercise programs that are feasible for community dissemination [8-10]. Numerous behavioral and psychosocial issues

Abbreviations: ADL $=$ activities of daily living, APA = adaptive physical activity, AUSL = Azienda Unità Sanitaria Locale, BBS = Berg Balance Scale, GDS = Geriatric Depression Scale, $\mathrm{QOL}=$ quality of life, SIS = Stroke Impact Scale, SPPB = Short Physical Performance Battery, VA = Department of Veterans Affairs.

* Address all correspondence to Francesco Benvenuti, MD; Dipartimento della Riabilitazione, AUSL 11, Regione Toscana, Piazza XX Settembre 13, 56028 San Miniato (Pisa), Italy; 0571-705713; fax: 0571-705718.

Email: f.benvenuti@usl11.tos.it

DOI: 10.1682/JRRD.2007.02.0025 
associated with chronic disability and aging influence exercise adherence and can serve as barriers to such health-promoting behaviors [9]. While both home- and hospital-based programs are reported in the literature $[4,8,11]$, the exercise settings and behavioral reinforcement strategies that are optimal for improving mobility and quality of life (QOL) outcomes are unknown.

Based on task-oriented exercise and social learning models that facilitate exercise behaviors in frail older adults, we developed a structured adaptive physical activity (APA) program with gymnasium and home components for chronic stroke survivors [7-8,12-13]. Group exercises targeting improved gait and balance were used to enhance social support, with a parallel home exercise regimen to build self-efficacy for habitual physical activities that enhance daily function and QOL. This pilot study investigated the efficacy of APA for improving mobility, activities of daily living (ADL) profiles, and strokespecific outcomes related to QOL in chronic stroke survivors as a step toward community-based clinical trials.

\section{METHODS}

Men or women $>40$ years with mild-moderate hemiparetic gait following stroke ( $>9$ months) were recruited from Azienda Unità Sanitaria Locale (AUSL) 11 of the Tuscany region in Italy. Mild-moderate hemiparetic gait was defined as visible asymmetry with reduced gait stance or reduced stance, increased swing time, and the ability to ambulate $>10 \mathrm{~m}$ (with assistive device as needed). Participants received medical clearance from their general practitioner and the Rehabilitation Health Authorities, and all subjects provided informed consent, consistent with the Helsinki Declaration. The Mini-Mental State Examination and Geriatric Depression Scale (GDS) were used to screen for dementia and depression, respectively [14-15]. Exclusion criteria included dementia, severe aphasia, heart failure, or other medical condition(s) that precluded participation in low-intensity exercise [16].

APA consisted of 2 months of twice weekly, 1-hour sessions of group mobility, balance, and stretching exercises at the hospital gymnasium. Mobility training included subjects walking for 12 minutes on a course outfitted with parallel bars to practice stepping over $10 \mathrm{~cm}$ high boards, traversing 3 steps, and walking laterally, all with handrail support. Exercises at the parallel bars included weight shift from leg to leg, half-squat, turn in place, leg-trunk flexion, and extension exercises (eight repetitions of each). Seated upper- and lower-limb stretching exercises that focused on range of motion, including trunk mobility, constituted the remainder of the hour and provided interim rest periods between the more physically demanding activities. As approved by the study physical therapist, participants performed a similar home regimen three times a week that included walking, stair climbing, and stretching exercises. Class was conducted with a ratio of one physical therapist to eleven participants, with compliance monitored at each gymnasium visit by the study coordinator, who verified participation using participants' diary-logbook.

We administered a battery of standardized instruments for two baseline assessments one month apart to establish neurological status stability and repeated the testing $<1$ week posttraining. The Motricity Index measured stroke impairments [17-18]. Mobility function was evaluated with the Short Physical Performance Battery (SPPB) [19-20], 6-minute walks [7], and the Berg Balance Scale (BBS) [21]. The Barthel Index and Lawton scores were used to assess basic and instrumental ADL profiles [22-23]. The Stroke Impact Scale (SIS) examined participant-rated outcomes related to QOL [24]. Since both exercise and social support can affect mood, the GDS was repeated after APA [25]. Evaluators were not blinded in this uncontrolled pilot study.

All data are expressed as mean \pm standard error with significance at $p<0.05$ (two-tailed). Paired $t$-tests examined differences between repeated baseline and pre- versus posttraining timed walks. Wilcoxon matched pairs signed rank tests evaluated nonparametric variables. We used simple regression to examine relationships between variables and their change across APA.

\section{RESULTS}

Of the 22 subjects who were enrolled, 20 completed the APA program. One dropped out because of an injury unrelated to the study; one subject withdrew after $<2$ weeks of being noncompliant to the program. Participants who completed the APA included 11 women and 9 men, age $70 \pm 1.7$ years (range 55-85) who were $56 \pm 19$ months (range 9-306) poststroke, with body mass index $28.6 \pm 1.1$ (range 23-42). No differences were found on any measures between baselines 1 and 2 (Table 1). The GDS revealed 79 percent of participants had scores $>6$, 
Table 1.

Repeated baseline and post-adaptive physical activity (APA) impairment, mobility function, and basic and instrumental activities of daily living (ADL) data for 20 individuals who completed program. Data are mean \pm standard error; $p$-values test significance between mean of baseline versus post-APA training.

\begin{tabular}{lcccc}
\hline \multicolumn{1}{c}{ Outcome Variable } & Baseline 1 & Baseline 2 & Post-APA & $\boldsymbol{p}$-Value \\
\hline Motricity Index & & & & 0.002 \\
$\quad$ Upper Limb & $6.6 \pm 1.1$ & $6.5 \pm 1.1$ & $8.7 \pm 1.3$ & 0.016 \\
Lower Limb & $7.6 \pm 0.8$ & $7.5 \pm 0.8$ & $9.2 \pm 1.0$ & $0.2^{*}$ \\
Trunk Control & $75.5 \pm 5.0$ & $76.8 \pm 4.7$ & $78.1 \pm 5.6$ & 0.005 \\
6-Minute Walk Distance (m) & $116 \pm 15$ & $113 \pm 14$ & $142 \pm 17$ & 0.001 \\
Berg Balance Scale & $34.0 \pm 2.0$ & $35.0 \pm 1.7$ & $45.0 \pm 1.6$ & 0.001 \\
Short Physical Performance Battery (total) & $3.15 \pm 0.44$ & $3.30 \pm 0.41$ & $5.15 \pm 0.60$ & 0.001 \\
Barthel Index & $74.8 \pm 4.0$ & $75.3 \pm 3.9$ & $83.8 \pm 3.7$ & $0.9^{*}$ \\
Lawton Instrumental ADL Scale & $63 \pm 4$ & $65 \pm 4$ & $64 \pm 4$ & \\
"Not significant. &
\end{tabular}

indicating significant depressive symptoms [25]. Training compliance was 97 percent attendance for classes, with full compliance to home exercise. Two individuals complained of minor back pain, which was transient and did not interrupt training. No study-related adverse events occurred.

\section{Functional Outcomes}

APA reduced stroke impairments and improved all mobility outcomes (Table 1). Motricity Index paretic upper- and lower-limb scores improved. Six-minute walk distances increased 24 percent and BBS scores 10 points. SPPB and all subscales improved (Figure). APA improved basic but not instrumental ADL scores. The Barthel Index improved by 9 points, while Lawton scores

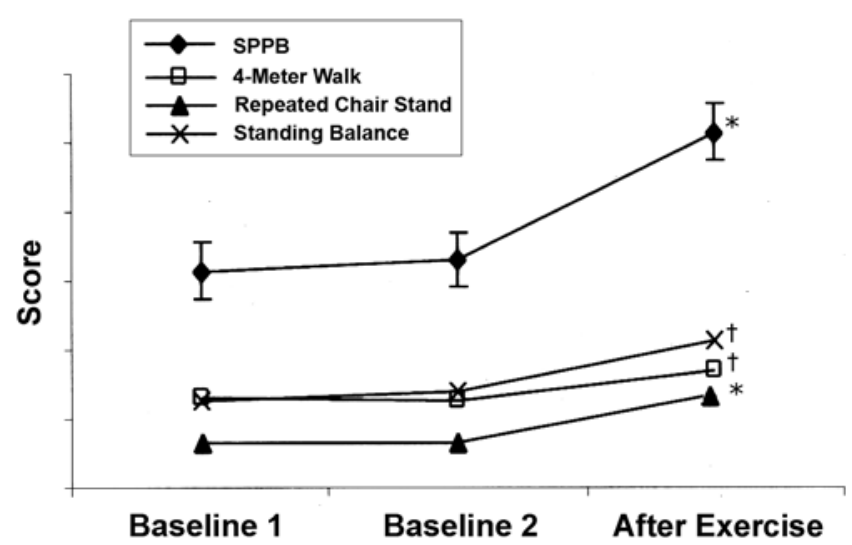

Figure.

Short Physical Performance Battery (SPPB) composite and subscores at repeated baseline testing and post-adaptive physical activity. Data are mean \pm standard error for SPPB composite score. ${ }^{*} p<0.001,{ }^{\dagger} p<0.03$. were unchanged. No relationships were found between age or latency since stroke and improvements with APA in any functional outcome measures $(p>0.2)$.

\section{Quality of Life Related Outcomes}

SIS Mobility, Participation, and Recovery improved during APA (Table 2), with a trend toward improved Activity $(p=0.053)$ and Memory $(p=0.06)$. GDS scores also improved, but the proportion of subjects with scores indicating significant depressive symptoms was not significantly different (15/19 vs $12 / 19$, pre- vs post-APA, $p=0.2$ ). Improved GDS scores were related to increased SIS Mobility ( $r=0.36, p=0.01$ ) but unrelated to any other outcomes.

\section{DISCUSSION AND CONCLUSIONS}

The major finding is that a 2-month APA program reduced stroke impairments and improved mobility function in individuals with chronic stroke. The gains in gait and balance translate into improved basic but not instrumental ADL profiles. APA further improved selected SIS domains and depression scores. These findings provide evidence that a group exercise class combined with a home program is effective in reducing stroke impairments and improving mobility function and QOL-related outcomes for older chronic stroke survivors.

The functional gains with APA are robust and clinically significant. BBS scores improved 10 points, including 70 percent with gains $>6$ points. A 6 -point increase in BBS is clinically important [26], while a 10-point difference 
JRRD, Volume 45, Number 2, 2008

Table 2.

Repeated baseline and post-adaptive physical activity (APA) Geriatric Depression Scale and Stroke Impact Scale (SIS) scores. Data are mean \pm standard error. Significance values are for Wilcoxon matched pairs signed rank tests between mean of baseline versus post-APA training.

\begin{tabular}{|c|c|c|c|c|}
\hline Outcome Variable & Baseline 1 & Baseline 2 & Post-APA & $p$-Value \\
\hline Geriatric Depression Scale & $9.6 \pm 1.0$ & $9.5 \pm 0.9$ & $7.7 \pm 0.9$ & 0.01 \\
\hline \multicolumn{5}{|l|}{ SIS } \\
\hline Mobility & $54 \pm 5$ & $55 \pm 6$ & $74 \pm 6$ & 0.002 \\
\hline Participation & $30 \pm 6$ & $31 \pm 5$ & $40 \pm 5$ & 0.03 \\
\hline Recovery & $48 \pm 5$ & $45 \pm 5$ & $57 \pm 5$ & 0.03 \\
\hline Activity & $42 \pm 6$ & $43 \pm 6$ & $48 \pm 5$ & 0.053 \\
\hline Communication & $69 \pm 4$ & $69 \pm 4$ & $70 \pm 6$ & $0.15^{*}$ \\
\hline Force & $36 \pm 6$ & $32 \pm 5$ & $38 \pm 5$ & $0.12^{*}$ \\
\hline Hand & $24 \pm 7$ & $21 \pm 6$ & $35 \pm 8$ & $0.15^{*}$ \\
\hline
\end{tabular}

predicts reliance on a less-dependent assistive device and discharge destination [27]. Six-minute walk distances increased 24 percent, similar to gains reported with 6 months of treadmill training [28]. We found that APA produced a significant increase in Barthel Index scores. In contrast, a randomized study of 3 months of communitybased physiotherapy in 359 chronic stroke patients found only modest gains in gait speed and no change in Barthel Index [29]. Why APA improved basic but not instrumental ADL profiles is unclear but may relate to the task-specificity of APA for targeting mobility exercises. By contrast, the finding of improved upper-limb Motricity Index scores was unexpected since functional upper-limb training was not a formal component of the APA program. However, many of the APA exercises did engage the affected upper limb, and the gains in gait and balance may have enabled more effective upper-limb use during daily activities leading to improved Motricity Index scores. Our results add to a growing body of literature that intensive task-specific training can improve key functional outcomes, including gait and balance, in chronic stroke patients. [30-33]

Recent studies have focused on group exercise models for chronic stroke that may be administered in a more cost-effective manner at the community level. A number of training programs including modified cycle ergometry, water aerobics, treadmill, and lower-limb group exercises are proven in randomized studies to increase fitness levels and selected functional outcomes [34]. Four weeks of treadmill combined with overground walking training is reported to increase walking speed 20 percent but not improve stroke-specific disability indices in chronic hemiparesis [11]. A randomized study by Pang et al. found that a 19-week community exercise program improved leg strength and 6-minute walk distances but not BBS scores [8]. Similarly, regular water aerobics as well as aerobics plus strength training are reported to increase overground walking by 16 and 21 percent in chronic stroke survivors, respectively [35]. Our findings corroborate recent studies that structured group exercise programs that include components of weight-shifting and agility significantly improve mobility and balance for older individuals with chronic stroke deficits [36]. A unique aspect of APA is the combination of gymnasium work for social reinforcement and parallel home exercises to facilitate the transfer of mobility-related behaviors into daily habits. This combination may contribute to the observed improvements in multiple self-reported SIS domains related to QOL. Further studies are needed to determine the optimal setting(s) and dose intensity of exercise that durably improve function and QOL in the chronic stroke population.

In summary, APA improves gait and balance function, enhances basic ADL profiles, and improves GDS and SIS domains related to QOL poststroke. Our results are limited by the noncontrolled design, small sample size, and lack of blinding to outcomes. However, no differences were found between repeated baseline testing a month apart, which shows stability for all functional measures in subjects that are a mean $>4$ years poststroke and would otherwise not be expected to improve [37]. Since age of 85 years and latency of 25 years poststroke did not alter treatment response, APA has the potential to improve function and QOL for many individuals who are aging with the chronic disability of stroke. Larger studies 
are underway to determine whether community-based APA improves rehabilitation and health outcomes in the chronic stroke population.

\section{ACKNOWLEDGMENTS}

This material is the result of work supported with resources and the use of facilities at the Dipartimento della Riabilitazione, AUSL 11, Regione Toscana, Empoli; the Istituto Superiore di Sanità, Roma, Italy within the project, "Obtaining optimal functional recovery and efficient managed care for the chronic stroke population" (convenzione N. 530/F20/2); the Baltimore Department of Veterans Affairs (VA) Geriatric Research, Education, and Clinical Center; and the VA Rehabilitation Research and Development Exercise and Robotics Center of Excellence. We also thank the John E. Fogarty International Center for support.

The authors have declared that no competing interests exist.

\section{REFERENCES}

1. Ivey FM, Macko RF, Ryan AS, Hafer-Macko CE. Cardiovascular health and fitness after stroke. Top Stroke Rehabil. 2005;12(1):1-16. [PMID: 15735997]

2. Hafer-Macko CE, Yu S, Ryan AS, Ivey FM, Macko RF. Elevated tumor necrosis factor-alpha in skeletal muscle after stroke. Stroke. 2005;36(9):2021-23. [PMID: 16109906]

3. Ivey FM, Ryan AS, Hafer-Macko CE, Garrity BM, Sorkin JD, Goldberg AP, Macko RF. High prevalence of abnormal glucose metabolism and poor sensitivity of fasting plasma glucose in the chronic phase of stroke. Cerebrovasc Dis. 2006;22(5-6):368-71. [PMID: 16888377]

4. Duncan P, Studenski S, Richards L, Gollub S, Lai SM, Reker D, Perera S, Yates J, Koch V, Rigler S, Johnson D. Randomized clinical trial of therapeutic exercise in subacute stroke. Stroke. 2003;34(9):2173-80. [PMID: 12920254$]$

5. Rimmer JH, Riley B, Creviston T, Nicola T. Exercise training in a predominantly African-American group of stroke survivors. Med Sci Sports Exerc. 2000;32(12):1990-96. [PMID: 11128841]

6. Eich HJ, Mach H, Werner C, Hesse S. Aerobic treadmill plus Bobath walking training improves walking in subacute stroke: A randomized controlled trial. Clin Rehabil. 2004; 18(6):640-51. [PMID: 15473116]

7. Macko RF, Ivey FM, Forrester LW, Hanley D, Sorkin JD, Katzel LI, Silver KH, Goldberg AP. Treadmill exercise rehabilitation improves ambulatory function and cardiovascular fitness in patients with chronic stroke: A randomized, controlled trial. Stroke. 2005;36(10):2206-11.

[PMID: 16151035]

8. Pang MY, Eng JJ, Dawson AS, McKay HA, Harris JE. A community-based fitness and mobility exercise program for older adults with chronic stroke: A randomized, controlled trial. J Am Geriatr Soc. 2005;53(10):1667-74.

[PMID: 16181164$]$

9. Gordon NF, Gulanick M, Costa F, Fletcher G, Franklin BA, Roth EJ, Shephard T; American Heart Association Council on Clinical Cardiology, Subcommittee on Exercise, Cardiac Rehabilitation, and Prevention; the Council on Cardiovascular Nursing; the Council on Nutrition, Physical Activity, and Metabolism; and the Stroke Council. Physical activity and exercise recommendations for stroke survivors: An American Heart Association scientific statement from the Council on Clinical Cardiology, Subcommittee on Exercise, Cardiac Rehabilitation, and Prevention; the Council on Cardiovascular Nursing; the Council on Nutrition, Physical Activity, and Metabolism; and the Stroke Council. Circulation. 2004; 109(16):2031-41. [PMID: 15117863]

10. Rimmer JH, Nicola T, Riley B, Creviston T. Exercise training for African Americans with disabilities residing in difficult social environments. Am J Prev Med. 2002;23(4): 290-95. [PMID: 12406483]

11. Ada L, Dean CM, Hall JM, Bampton J, Crompton S. A treadmill and overground walking program improves walking in persons residing in the community after stroke: A placebo-controlled, randomized trial. Arch Phys Med Rehabil. 2003;84(10):1486-91. [PMID: 14586916]

12. Shaughnessy M, Resnick BM, Macko RF. Testing a model of post-stroke exercise behavior. Rehabil Nurs. 2006;31(1): 15-21. [PMID: 16422040]

13. Resnick B, Vogel A, Luisi D. Motivating minority older adults to exercise. Cultur Divers Ethnic Minor Psychol. 2006; 12(1):17-29. [PMID: 16594852]

14. Folstein MF, Folstein SE, McHugh PR. "Mini-mental state.” A practical method for grading the cognitive state of patients for the clinician. J Psychiatr Res. 1975;12(3):189-98.

[PMID: 1202204]

15. Yesavage JA, Brink TL, Rose TL, Lum O, Huang V, Adey $\mathrm{M}$, Leirer VO. Development and validation of a geriatric depression screening scale: A preliminary report. J Psychiatr Res. 1982;17(1):37-49. [PMID: 7183759]

16. Macko RF, Smith GV, Dobrovolny CL, Sorkin JD, Goldberg AP, Silver KH. Treadmill training improves fitness reserve in chronic stroke patients. Arch Phys Med Rehabil. 2001;82(7):879-84. [PMID: 11441372]

17. Collin C, Wade D. Assessing motor impairment after stroke: A pilot reliability study. J Neurol Neurosurg Psychiatry. 1990;53(7):576-79. [PMID: 2391521] 
18. Wade DT, Collen FM, Robb GF, Warlow CP. Physiotherapy intervention late after stroke and mobility. BMJ. 1992; 304(6827):609-13. [PMID: 1559090]

19. Guralnik JM, Simonsick EM, Ferrucci L, Glynn RJ, Berkman LF, Blazer DG, Scherr PA, Wallace RB. A short physical performance battery assessing lower extremity function: Association with self-reported disability and prediction of mortality and nursing home admission. J Gerontol. 1994;49(2):M85-M94. [PMID: 8126356]

20. Guralnik JM, Ferrucci L, Pieper CF, Leveille SG, Markides KS, Ostir GV, Studenski S, Berkman LF, Wallace RB. Lower extremity function and subsequent disability: Consistency across studies, predictive models, and value of gait speed alone compared with the short physical performance battery. J Gerontol A Biol Sci Med Sci. 2000;55(4):M221-31. [PMID: 10811152]

21. Berg KO, Wood-Dauphinee SL, Williams JI, Maki B. Measuring balance in the elderly: Validation of an instrument. Can J Public Health. 1992;83 Suppl 2:S7-11. [PMID: 1468055]

22. Lawton MP, Brody EM. Assessment of older people: Selfmaintaining and instrumental activities of daily living. Gerontologist. 1969;9(3):179-86. [PMID: 5349366]

23. Mahoney FI, Barthel DW. Functional evaluation: The Barthel Index. Md State Med J. 1965;14:61-65. [PMID: 14258950]

24. Duncan PW, Wallace D, Lai SM, Johnson D, Embretson S, Laster LJ. The stroke impact scale version 2.0. Evaluation of reliability, validity, and sensitivity to change. Stroke. 1999; 30(10):2131-40. [PMID: 10512918]

25. Almeida OP, Almeida SA. Short versions of the geriatric depression scale: A study of their validity for the diagnosis of a major depressive episode according to ICD-10 and DSM-IV. Int J Geriatr Psychiatry. 1999;14(10):858-65. [PMID: 10521885]

26. Stevenson TJ. Detecting change in patients with stroke using the Berg Balance Scale. Aust J Physiother. 2001; 47(1):29-38. [PMID: 11552860]

27. Wee JY, Wong H, Palepu A. Validation of the Berg Balance Scale as a predictor of length of stay and discharge destination in stroke rehabilitation. Arch Phys Med Rehabil. 2003;84(5):731-35. [PMID: 12736890]

28. Macko RF, Ivey FM, Forrester LW. Task-oriented aerobic exercise in chronic hemiparetic stroke: Training protocols and treatment effects. Top Stroke Rehabil. 2005;12(1):45-57. [PMID: 15736000]

29. Green J, Forster A, Bogle S, Young J. Physiotherapy for patients with mobility problems more than 1 year after stroke: A randomised controlled trial. Lancet. 2002; 359(9302):199-203. [PMID: 11812553]

30. Rodriguez AA, Black PO, Kile KA, Sherman J, Stellberg B, McCormick J, Roszkowski J, Swiggum E. Gait training efficacy using a home-based practice model in chronic hemiplegia. Arch Phys Med Rehabil. 1996;77(8):801-5. [PMID: 8702375]

31. Dean CM, Shepherd RB. Task-related training improves performance of seated reaching tasks after stroke. A randomized controlled trial. Stroke. 1997;28(4):722-28. [PMID: 9099186]

32. Werner RA, Kessler S. Effectiveness of an intensive outpatient rehabilitation program for postacute stroke patients. Am J Phys Med Rehabil. 1996;75(2):114-20. [PMID: 8630191]

33. Chu KS, Eng JJ, Dawson AS, Harris JE, Ozkaplan A, Gylfadóttir S. Water-based exercise for cardiovascular fitness in people with chronic stroke: A randomized controlled trial. Arch Phys Med Rehabil. 2004;85(6):870-74. [PMID: 15179638]

34. Potempa K, Lopez M, Braun LT, Szidon JP, Fogg L, Tincknell T. Physiological outcomes of aerobic exercise training in hemiparetic stroke patients. Stroke. 1995;26(1):101-5. [PMID: 7839377]

35. Teixeira-Salmela LF, Olney SJ, Nadeua S, Brouwer B. Muscle strengthening and physical conditioning to reduce impairment and disability in chronic stroke survivors. Arch Phys Med Rehabil. 1999;80(10):1211-18. [PMID: 10527076]

36. Marigold DS, Eng JJ, Dawson AS, Inglis JT, Harris JE, Gylfadóttir S. Exercise leads to faster postural reflexes, improved balance and mobility, and fewer falls in older persons with chronic stroke. J Am Geriatr Soc. 2005;53(3): 416-23. [PMID: 15743283]

37. Jorgensen HS, Nakayama H, Raaschou HO, Olsen TS. Recovery of walking function in stroke patients: The Copenhagen Stroke Study. Arch Phys Med Rehabil. 1995; 76(1):27-32. [PMID: 7811170]

Submitted for publication February 2, 2007. Accepted in revised form July 5, 2007. 